\title{
The Analocy Between Vice and Disease FROM THE REPUBLIC TO THE TIMAEUS
}

\section{Introduction}

The analogy between vice and disease, whether it affects the individual or a collective class of citizens, is ancient in Greek literature. Combined with other comparisons, and sometimes more allencompassing analogies such as between the city and the cosmos, between the human body and the cosmos, and between the soul and the city, the scheme of the bodily disease is found in numerous passages to illustrate the appearance of vice'. Reciprocally, although less frequently, vice too appears to be a model to define some diseases, which may well be a sign that medicine is determined by an ethical and political normative agenda. A famous example of this interaction between vice and disease is to be found through the comparison Thucydides makes between the plague of Athens and civil strife ${ }^{2}$.

In the Platonic corpus, the analogy between vice and disease is also well attested ${ }^{3}$. Bodily diseases are a model to understand vice in the soul; and in a general sense, vice-taken as a defect of a natural being - sheds light on what should be defined as a disease. The question is whether this analogy remains a strict comparison between the condition of the soul and that of the body or if it points to a more [69] subtle causal interaction between the two. There is nothing certain, however; for the passage from an analogy between illness and vice to a causal interaction between the two schemes, if there is any, is carried out in an extremely cautious way by Plato. This paper aims at answering two questions: (1) is there a prevalence of the causal model of vice over that of the disease or vice versa? Or does neither predominate? (2) Is there a systematic interaction between bodily diseases and vice, or should we assume that these interactions are simply adventitious and accidental? In other words, how far can we go, within a dualist approach that strongly separates body and soul, in comparing such disruptions in the individuals and in the cities?

In the first section, I will give an overview of the functioning of the analogy between disease and vice in the Republic; bodily diseases seem to be the model, through the analogy, that accounts for the vice in the soul and in the city: vice, as bodily disease, is a disruption of a hierarchical structure. But we will see that the analogy between vice and disease may point to a stronger metaphor, insofar as there seem to be a privileged connection between physical diseases that come from a bad regimen and diseases of the soul.

In the second section, relying on a passage in book 10 of the Republic, I will try to show however that this analogy rests on an asymmetrical understanding of the two terms that are compared, without allowing any simple causality that links them. To put it in few words, Plato does not say that vice can come from a physical disease, whereas some diseases seem to emerge because of a

\footnotetext{
${ }^{1}$ See especially Lloyd (2003) for a clear overview of the use of these analogies in ancient Greek literature.

${ }^{2}$ On this comparison, and especially about civil strife, where the disease and the vice are connected by the fact that the one feeds the other: the dissolution of social bonds worsening the contamination, which, in return, dissolves these very bonds, until the city is scattered, see Macé (2010).

${ }^{3}$ See Lloyd (2003) and also Stalley (1981, 1995b, 1995a, 1996) whose work on the notion of punishment and responsibility from the Protagoras to the Laws, through the Republic and the Timaeus, shows the importance of the connection between disease and vice in the Platonic corpus.
} 
Renaut, Olivier. «The Analogy Between Vice and Disease from the Republic to the Timaeus ». In Psychology and Ontology in Plato, Luca Pitteloud \& Evan Keeling (eds.), 139:67-83. Cham: Springer International Publishing, 2019. https://doi.org/10.1007/978-3-030-04654-5_6. - pre-proof version.

bad condition of the soul. In the third section, I will confront the use of the analogy in the Timaeus where, as it is well known, "diseases of the soul" or vices are said to come from a bad condition of the body. I will show that this conclusion, which seems to be contradictory with the Republic, is in fact perfectly compatible with it, insofar as the Timaeus says at the same time that some diseases are conditioned by a vicious regime andflawed institutions. I will then conclude on what appears to be, in Plato, a strong normative theory of the diseases of the body.

\section{A Sketch of the Vice-Disease Analogy in the Republic}

\subsection{Vice as Disease}

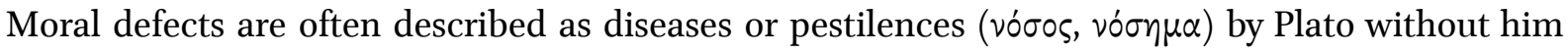
saying that they are so described through an analogy ${ }^{4}$.Vice is then characterized through what we can recognize as a metaphor: vice is a disease of the soul. But we should resist a little bit against the evidence that this metaphor is unquestioned and already lexicalized in the time of Plato. On the contrary, the metaphor is drawn from an analogy between the functioning of vice and that of illness, where one of the schemes clarifies the other, while the two remain relatively distinct. According to this analogy, vice is to the soul what disease is to the body. [69] The clearest formulation of the comparison between vice and disease is found in book 4:

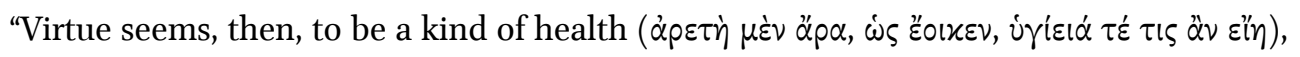

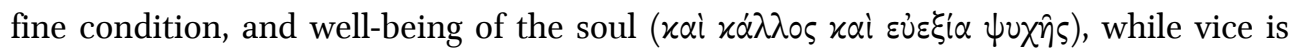

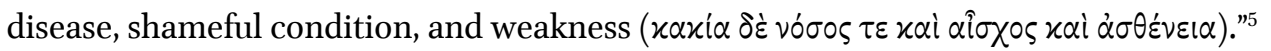

This formulation must be understood as the result of an analogy which is itself very clearly formalized:

"Because just and unjust actions are no different ( healthy and unhealthy things are for the body ( $\tau \hat{\omega} \nu \dot{\nu} \gamma(\varepsilon i v \hat{\omega} \nu \tau \varepsilon$ xai $\nu \circ \sigma \omega \delta \hat{\omega} \nu$, $\dot{\omega} \varsigma \dot{\varepsilon} x \varepsilon i v \alpha \dot{\varepsilon} \nu$

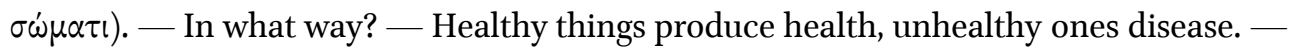
Yes.- And don't just actions produce justice in the soul and unjust ones injustice? Necessarily. - To produce health is to establish the components of the body in a natural relation of control and being controlled, one by another $(\tau \dot{\alpha} \dot{\varepsilon} \nu \tau \hat{\omega} \sigma \dot{\omega} \mu \alpha \tau \iota x \alpha \tau \dot{\alpha}$

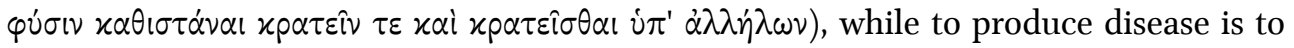
establish a relation of ruling and being ruled contrary to nature ( $\tau \dot{\delta} \delta \dot{\varepsilon} v o ́ \sigma o \nu \pi \alpha \rho \dot{\alpha} \varphi \dot{v} \sigma v$

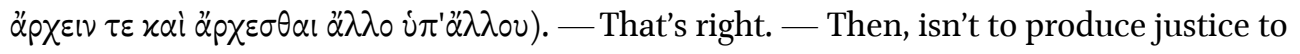
establish the parts of the soul in a natural relation of control, one by another $(\tau \dot{\alpha} \dot{\varepsilon} \nu \tau \hat{\eta}$

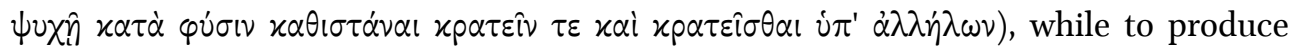
injustice is to establish a relation of ruling and being ruled contrary to nature ( $\tau \dot{\partial} \delta \dot{\varepsilon}$

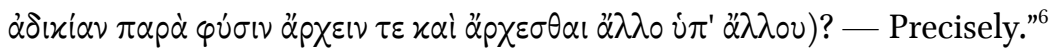

Justice is to the soul what health is to the body, and injustice is to the soul what illness is to the body. This analogous relation therefore designates vices and diseases as a subversion of a natural and hierarchical structure. As the elements or humors of the body must obey a kind of equilibrium,

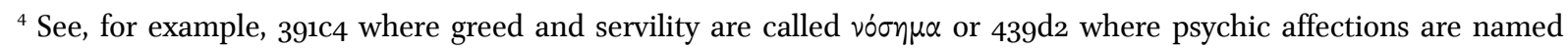

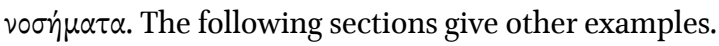

${ }^{5}$ Rep. 4, $444 \mathrm{~d}_{13}$ e2. All translations are taken from the Republic, trans. G.M.A. Grube, revised by C.D.C. Reeve, in Cooper \& Hutchinson (1997), unless specified

${ }^{6}$ Rep. 4, 444C5-d11.
} 
Renaut, Olivier. «The Analogy Between Vice and Disease from the Republic to the Timaeus ». In Psychology and Ontology in Plato, Luca Pitteloud \& Evan Keeling (eds.), 139:67-83. Cham: Springer International Publishing, 2019. https://doi.org/10.1007/978-3-030-04654-5_6. - pre-proof version.

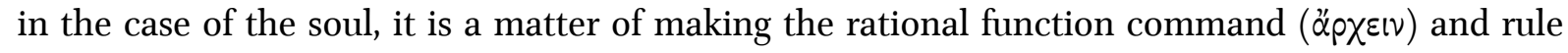
over ( analogy, the healthy or sick body appears to be the model from which the structural operations of the virtuous/vicious soul are described. It is then perfectly possible to call vice a "disease" as a result of the comparison. The analogy may naturally lead to a metaphor that erases in its formula the trace of the analogy.

\subsection{Disease as Vice}

The identification between vice and disease goes also the other way round. Disease can certainly be called a "vice" of the body. To begin with, disease is an "evil" ( $x \alpha x^{i} \alpha$ ), a defect, an incapacity, or a damage of the body as a whole or of one ofits parts; in that sense, a bodily disease is a failure for a nature to fulfill its function [70] (Épróv). ${ }^{7}$ This is why bodily diseases themselves are sometimes subject to moral judgment, just as love, drunkenness, or other "misfortunes" are (396d).

It is nevertheless difficult to discriminate between a neutral meaning of xaxós ("bad") and an ethical meaning which ordinarily translates $x \alpha x i \alpha$ by "vice." Whereas one is usually inclined to deplore and pity some natural misfortunes that come from necessity and chance-for example, being born with a puny bodily constitution ${ }^{8}$ - some bodily diseases are clearly the symptom of a vicious regime, which should arouse blame. A short passage in book 3 shows that the etiology of the disease is ethically determined:

“And doesn't it seem shameful to you to need medical help, not for wounds ( $\tau p \alpha \nu \mu \alpha \dot{\tau} \tau \omega \nu)$

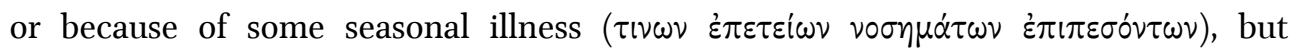
because, through idleness and the life-style ( $\left.\delta^{\prime} \alpha i \tau \alpha \nu\right)$ we've described, one is full of gas

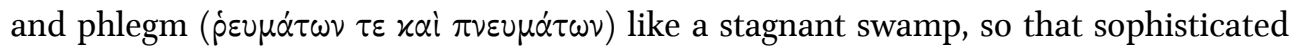
Asclepiad doctors are forced to come up with names like "flatulence" and "catarrh"

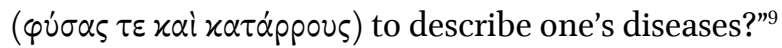

There are then some diseases that we should pity and cure and others that are shameful and fall under the scope of the legislator. So just as moral defect is a kind of disease, bodily disease is, in a way, a vice - and if not a moral vice, at least a functional vice. A certain normativity is at stake in both cases, vice and illness.

What we learn from the analogy so far is that the body and the soul function as hierarchical structures or orders ${ }^{10}$. Each element or function of this structure has its own natural place, just as the whole structure has a nature to ensure its proper function. Health and virtue are the names of the two positive modalities that constitute the good of what they apply to, whereas disease and vice are the two negative poles. But strictly speaking, the analogy does not tell us yet-it is not its function - about the entanglement between the effects of virtue on health, disease on vice, and vice versa ${ }^{11}$.

\footnotetext{
${ }^{7}$ This point is underlined by Stalley (1981, p. 112).

${ }^{8}$ This idea is clearly stated by Protagoras: Prot. $323 \mathrm{c} 8-\mathrm{d} 6$.

${ }^{9}$ Rep. 3, 405c8-d4.

${ }^{10}$ Miller (1962).

${ }^{11}$ Again, this point is rightly stated by Stalley (1981, p. 111), when he remarks that the analogy is limited, for it does not state any precise correspondence between parts of the soul and bodily parts and about the kind of "control" that should prevail in health and justice.
} 
Renaut, Olivier. «The Analogy Between Vice and Disease from the Republic to the Timaeus ». In Psychology and Ontology in Plato, Luca Pitteloud \& Evan Keeling (eds.), 139:67-83. Cham: Springer International Publishing, 2019. https://doi.org/10.1007/978-3-030-04654-5_6. - pre-proof version.

\subsection{The Analogy Applied to the City}

Not only the individual body and soul are characterized by the medical lexicon of illness. The collective body of citizens, and its regime, or even its constitution (or its soul) also receives the same qualifiers. At 470c5-10, Plato speaks of a "sick" city ( ( $0 \sigma \varepsilon \hat{\imath})$ engaged in an internal war

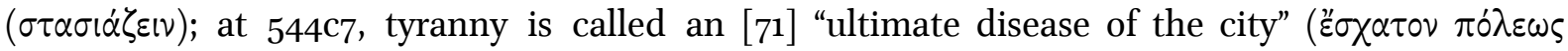

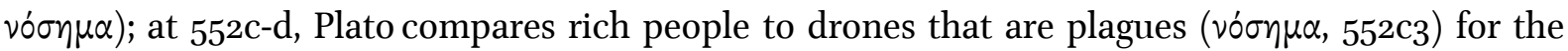
hive; the same disease ( $\tau \alpha \dot{\tau} \tau o ́ v . . . v o ́ \sigma \eta \mu \alpha, 5^{6} 3 \mathrm{e} 7$ ) that happened within oligarchy paving the way for

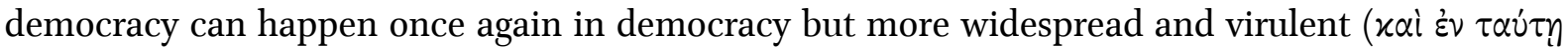

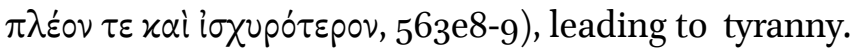

How should we account for this extension of the analogy on political bodiesand souls?

A first reason is that after all, if any structure can be called "healthy" when it is in order, nothing prevents us from applying the model of the bodily disease on this collective body that is the city when it is disorganized ${ }^{12}$. The general principle, according to which a disruptive change is expected in a structure when it undergoes an excessive external action, destroying its natural order and constitution, is recalled by Plato about tyranny:

"In fact, excessive action ( $\tau \dot{\partial} \not \partial \gamma \alpha \nu \tau \iota)$ in one direction usually sets up a change $(\mu \varepsilon \tau \alpha \beta 0 \lambda \eta \nu)$ in the opposite direction. This happens in seasons, in plants, in bodies, and,

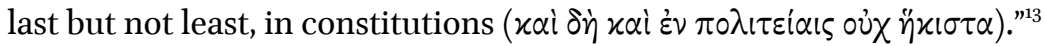

The illness model applies, so it seems, directly to the political "body" to account for its corruption, provided that, as a structure (which a body is), a political body undergoes some passions that threaten its external and internal balance. In that sense, it is fair to speak of a pathology, which relies on the general principle that all kinds of structures are to be understood in the same way through their own capacity for actions and passions ${ }^{14}$. The most fearful disease of the city, civil strife and internal war, is a result of a disruption of the natural laws that prevented one part to rule over the others with iniquity ${ }^{15}$.

Again, bodily disease seems to be the explanatory model for degenerated cities. The analogy between vice of the city and illness of the body is mentioned at least once in this context but this time to underline an internal disruption:

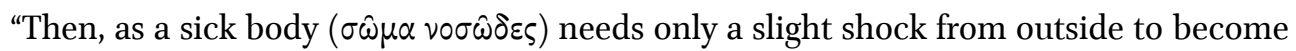

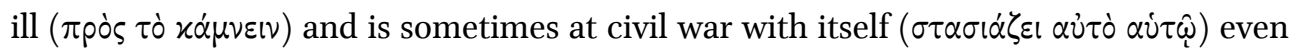
without this, so a city in the same condition needs only a small pretext-such as one side bringing in allies from an oligarchy or the other from a democracy - to fall ill and to fight with itself ( war even without any external influence. ${ }^{m 6}$

[72] In the first explanation, a city as a whole could be defined as a structure, comparable with any kind of plants and bodies. But this passage contains, if only implicitly, a second kind of explanation.

\footnotetext{
${ }^{12}$ On the presence of this analogy between bodily disease and political corruption in the ancient corpus, see Brock (2000) and Kosak (2000).

${ }^{13}$ Rep. 8, 563e9-564a1, trans. Grube slightly modified.

${ }^{14}$ See Phdr. 270c and on this passage Mansfeld (1980). On the homogenous ontology that prevails to account for a "nature" in the Platonic corpus through action and passion, and even the moral and political structures, see Macé (2006), esp. $178 \mathrm{ff}$.

${ }^{15}$ See Rep. 8, 564a1o-c4, where stinged and stingless drones in the hive are compared with phlegm and bile in the body. It is then up, respectively, to the lawgiver and the doctor to set up the balance again.

${ }^{16}$ Rep. 8, 556e3-9.
} 
Renaut, Olivier. «The Analogy Between Vice and Disease from the Republic to the Timaeus ». In Psychology and Ontology in Plato, Luca Pitteloud \& Evan Keeling (eds.), 139:67-83. Cham: Springer International Publishing, 2019. https://doi.org/10.1007/978-3-030-04654-5_6. - pre-proof version.

A city is not only a homogenous structure: it contains substructures-its citizens-that are relatively autonomous components that can be themselves vicious. We should then remember that the city itself is analogously compared with the soul in the Republic. This is not the place here to recall the meaning and the demonstrative value of the city-soul analogy; but this powerful analogy allows Plato to produce complex interactions, even a quasi-causality, between the individual and the political spheres. ${ }^{17}$ The lexicon of illness can be applied to the social body because the soul and the city are comparable structures and in some cases eponymous. As a result, as physical diseases certainly affect not only individual bodies but also series of bodies, for example, in the case of a plague, individual vicious souls in a city finally mark the cities with their character, and, conversely, corrupted cities give birth to vicious and diseased souls within them. It is then by contamination of its parts (individual souls) that a city becomes sick, and it is by shaping vicious souls through bad education that a city makes its citizens likely to be sick themselves and prone to injustice ${ }^{18}$.

\subsection{Two Kinds of Diseases}

If the vice-disease analogy, which rests on a strong distinction between the soul and the body, seems viable to us, it is because the two terms that are compared (soul and body) remain quite distinct. But this point is not without difficulty, and the power of the metaphor should not be dismissed. What meaning does Plato want to convey when he speaks about a "diseased soul" or a "fevered city"? Why, in other words, does the metaphor of a diseased soul or city seem to conceal a surplus of meaning in the Republic? It is not only because vice and disease are names of disrupted structures that they can be compared, it is because there are some interactions between the order of the soul and that of the body. However, these interactions are not detailed in the Republic, or, to be fairer, they are presented in an extremely cautious way.

At the origin of the vice-disease analogy, there is a quite tangible problem: how should we shape characters to make them just, them and the city they belong to, and who is responsible of this education? A contest seems to occur between doctors and masters of paideia in the fevered city

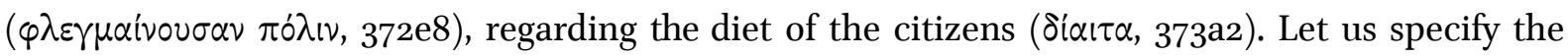
relationship between these two arts.

First of all, medicine is intimately associated with gymnastics in the sense that, in the context of the city being built from book 2, these two arts refer to a good diet [73] or regimen in order to produce health and power ${ }^{19}$. The concern for diseases emerges through the example of those athletes "who sleep their lives away" (404a5), being brought up by a bad regimen favoring sluggishness and idleness - a regimen that Socrates had already ridiculed in the Gorgias calling it

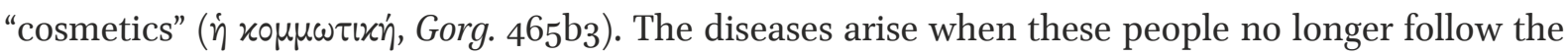
special diet prescribed for them. It is therefore necessary to distinguish between the true and the false doctors-coaches with regard to sickness and health, as we must distinguish between the true and the false masters of music and gymnastics with respect to indiscipline and moderation.

“Just as variety ( $\dot{\eta} \pi \circ \cdots(\lambda i \alpha)$ in the one gives rise to licentiousness ( $\dot{\alpha} x \circ \lambda \alpha \sigma i \alpha \nu)$, doesn't it

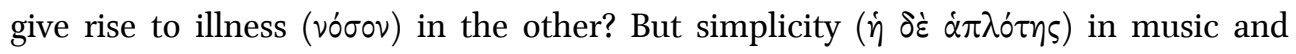

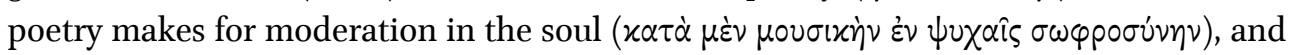

\footnotetext{
${ }^{17}$ On this point, see Blössner (2007) and Renaut (2017). On the metaphor of the sick city in Plato, see Lloyd (2003, pp. 156-157).

${ }^{18}$ Even if the general principle that affects every structure works, political instability does indeed come from the parts of the city as its vehicles (see Rep. 4, 435e1-436a3).

${ }^{19}$ See the first association in 389ci-6.
} 
Renaut, Olivier. «The Analogy Between Vice and Disease from the Republic to the Timaeus ». In Psychology and Ontology in Plato, Luca Pitteloud \& Evan Keeling (eds.), 139:67-83. Cham: Springer International Publishing, 2019. https://doi.org/10.1007/978-3-030-04654-5_6. - pre-proof version.

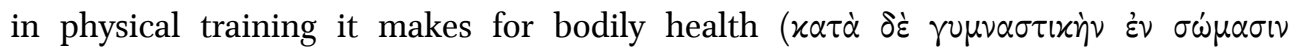

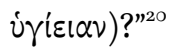

This passage presents, again, an analogy between virtue/vice and health/disease, through the respective effects of music (on the soul) and gymnastics (on the body). The disease and the malignant disposition of the body is therefore an analogue of the indiscipline in the soul. However, as Socrates states repeatedly hereafter, music and gymnastics are intended to the shaping of the soul, insofar as these two arts aim at shaping good characters. Then, it is necessary to have in mind the difference between gymnastics and medicine, insofar as medicine seems, in some passages, restricted to a localized curative activity on bodily parts.

"Therefore, won't we say that Asclepius knew this and that he taught medicine for those

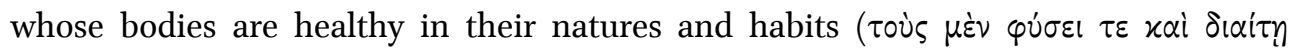
iү

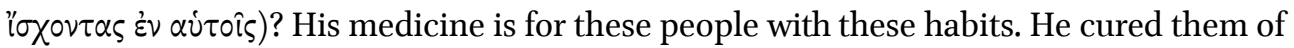
their disease with drugs or surgery and then ordered them to live their usual life so as not to harm their city's affairs. But for those whose bodies were riddled with disease, he didn't attempt to prescribe a regimen, drawing off a little here and pouring in a little there, in order to make their life a prolonged misery and enable them to produce offspring in all probability like themselves. He didn't think that he should treat someone who couldn't live a normal life, since such a person would be of no profit either to himself or to the city."21

Two strands of medicine are distinguished in this passage: on the one hand, a sophisticated medicine with deleterious effects in prescribing for each diseased individual a specific regimen that actually feeds his puny constitution and on the other hand a medicine that takes into account the political existence and function of the individuals in the city $^{22}$. Having a better sense of what is just, the medicine of [74] Asclepius is then more able to bring about health in the city. The operations on the body are then much simpler (or presented as such) than the sophisticated medicine, for the physician should heal only some localized affections and prescribe a normal regimen - the diseases at stake here are probably those, as we saw earlier, "wounds" and "seasonal illnesses" (405c8-9), diseases that do not come from indiscipline and the physical effects of an indolent diet. But as a result, medicine is here consciously reduced to a technique of intervention on the body, certainly concerned with the diet and exercise favoring health, but not encroaching on the function of education by music and gymnastics which aims at producing moral qualities in the individual.

We may then give two meanings of "disease" in Republic 3. A first meaning of "disease" refers to natural diseases, the "seasonal diseases" as Socrates calls them, whose principle is external and whose treatment requires a medicine that aims at an immediate restoration of the natural order of the body by drugs and other kinds of treatment. A second meaning refers to the "new diseases," such as the "flatulences and catarrhs," which are the effects and the symptoms of a depraved, varied, and uncontrolled regimen and whose treatment requires a sophisticated medicine which actually worsens the state of the city. As the example of the oligarch in book 8 shows (556e3-9), the

\footnotetext{
${ }^{20}$ Rep. 3, 404e3-5 (trans. Grube \& Reeve slightly modified).

${ }^{21}$ Rep. 3, 407c7-e2.

${ }^{22}$ On this passage, and the reconstruction of an idealized history of medicine, see the very insightful remarks of Demont (2013). See also Jorgenson (2018, pp. 111-117) and finally Betegh in a paper entitled "Plato on illness in the Phaedo, the Republic, and the Timaeus" (forthcoming).
} 
Renaut, Olivier. «The Analogy Between Vice and Disease from the Republic to the Timaeus ». In Psychology and Ontology in Plato, Luca Pitteloud \& Evan Keeling (eds.), 139:67-83. Cham: Springer International Publishing, 2019. https://doi.org/10.1007/978-3-030-04654-5_6. - pre-proof version.

idleness and sluggishness of the regimen make the individual more vulnerable to natural physical diseases and wounds.

The first kind of disease presupposes that in some cases, the physician is able to isolate the sphere of the body with a very localized treatment, even if medicine as a whole concerns a general regimen that prevents people from being vulnerable to other illnesses. The second kind of disease, by contrast, is mingled with moral, social, and political habits and way of life, so that it is fair to say that "flatulences and catarrhs" are diseases that come from and reveal a "disease of the soul." Both kinds of disease imply, as is obvious, a strong normative view of medicine: the old medicine, which is concerned with the overall good of the individual in his social and political environment, is expected to have some grasp of what is good, and not only to what is healthy, even if its procedure seem to be reduced here to prescribe a correct diet, together with localized interventions; the new medicine, by contrast, has no insight of the overall good of the individual, by focusing exclusively on the bodily condition. Without playing with words, these "new diseases" and diseases of the soul are feeding each other in a "vicious" circle.

To conclude this section, we have seen that the virtue-health/vice-disease analogy rests on a strict isomorphism between the body and the soul (or city), both being a naturally measured and ordered structure; but we have also seen that there is a more privileged association between vice and disease insofar as vice can contribute to the emergence of new diseases and physical weaknesses, making the metaphor of the "disease of the soul" more vivid. A pending issue is the following: how far should we accept that there is a causality at stake, beyond the analogy, between the diseases of the soul and the ones of the body? An important passage in book 10 of the Republic shows that Plato is very cautious on this interaction and refutes any direct causation between body and soul regarding evil.

\section{Republic 10: The Analogy Reconsidered}

[75] In book 10 of the Republic, Socrates sets up an argument to prove the immortality of the soul (6o8c-611a). A first premise claims that there is a natural good and evil for each thing, so that one thing perishes because of the development of its own evil. A second claim is that if a thing is not even destroyed by its own natural evil, then that thing is immortal. In what follows, I will not focus on the validity of the argument ${ }^{23}$ but only on the vice-disease analogy, which is further elaborated and tellsus more about a possible causality between the body and the soul.

(1) First, the analogy recalls the structural homology of disease and vice, both being a disruption of the organized and hierarchical structure.

"And do you say that there is a good and a bad for everything? For example, ophthalmia

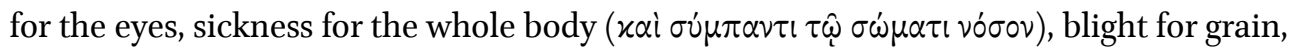
rot for wood, rust for iron or bronze. In other words, is there, as I say, a natural badness

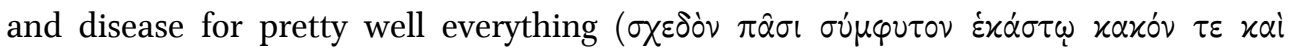

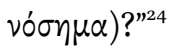

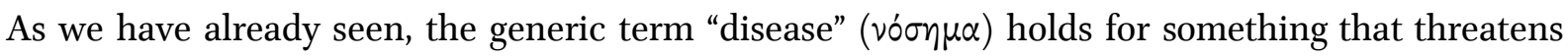
and finally corrupts whatever thing's natural order: this term can be used in an analogous way for natural elements, metals, organs, or animal. A disease is, in other words, a "defect" that prevents the

\footnotetext{
${ }^{23}$ On the structure and validity of the argument, see Brown (2011).

${ }^{24}$ Rep. 10, 6o8e6-6oga4 (trans. Grube slightly modified).
} 
Renaut, Olivier. «The Analogy Between Vice and Disease from the Republic to the Timaeus ». In Psychology and Ontology in Plato, Luca Pitteloud \& Evan Keeling (eds.), 139:67-83. Cham: Springer International Publishing, 2019. https://doi.org/10.1007/978-3-030-04654-5_6. - pre-proof version.

thing from fulfilling its nature or natural activity. It is called "sickness" for any physical body, and it is "vice" for a soul (6ogb9-c1).

Even if this general principle could apply to everything (and in this respect a soul could be well compared with metal), it is precisely the analogy of vice of the soul and disease of the body that Socrates calls upon in the argument.

"Just as the body is worn out, destroyed, and brought to the point where it is abody no

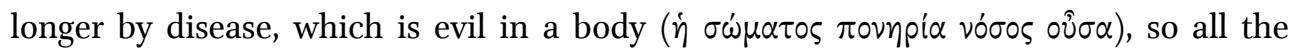
things we mentioned just now reach the point at which they cease to be what they are

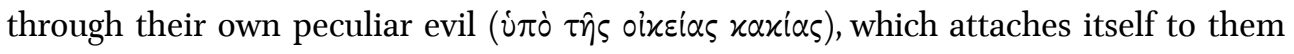
and is present in them. Isn't that so? - Yes. - Then look at the soul in the same way

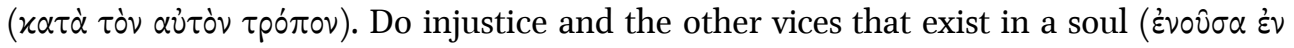
$\alpha \dot{v} \tau \hat{\eta} \dot{\alpha} \delta x x^{\prime} \alpha$ xai $\dot{\eta} \dot{\alpha} \lambda \lambda \eta x \alpha x^{\prime} \alpha$ ) - by their very presence in it and by attaching themselves to it-corrupt it and make it waste away until, having brought it to the point of death,

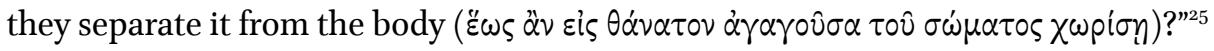

This homology leads us to a second point.

(2) Second, the analogy reveals a difference and even a specificity of the soul: by contrast with the body, a soul will not perish because of the injustice it possesses.

In the passage quoted just above, the analogy is brought up in a strict way to raise a difficult question. A disease makes the body waste away and perish, "to the point [76] where it is a body no longer"; we can well imagine a body perish so as to become nothing but matter and dust. The first question at stake is not whether the disease of the soul, vice, disrupts the order of the soul-this is a claim that we already have seen previously in the Republic-but whether it has the same outcome as in the body, that is, that the soul itself perishes, not being recognized as a soul anymore. Another related question is whether the presence of vice, by corrupting the soul, is responsible for "death," i.e., the separation of the soul from the body (making the body a mere corpse), whereas it is not said that bodily diseases lead to the same outcome ${ }^{26}$. The strict way of positing the analogy is important here, for it does not only reveal an isomorphism between soul and body but also a specificity or a difference between the two. By contrast with the body, which perishes because of its own disease, the soul remains unjust, but does not perish: being unjust does not, obviously, lead to death.

This point leads to a third issue: if the body and the soul are comparable throughout the analogy, but are distinct insofar as the latter may not perish whereas the former does, producing "death," then, what is the causal relation between the two that can account for this separation between body and soul?

(3) Third, and because "death" is involved, Socrates raises the issue of the causal interaction between a soul and the body it enlivens. A corrupted body should not infect, at least directly, the soul with its own disease. If the body has any power on the soul, it is because, in a way, the soul makes room in itself for disruption and lets itself be infected by the desires that come from the body.

Socrates focuses first on the causal relation between food and the body.

\footnotetext{
${ }^{25}$ Rep. 10, 6o9c5-d7.

${ }^{26}$ See Adam (1969, p. 423) ad. 6ogd and 425 ad. 61od. Adam is right to distinguish three possible meanings of "death" (a) of the body, (b) of the soul, and (c) of the sunolon. This ambiguity between an ordinary meaning of "death" and the more strict Platonic version of it, i.e., separation between body and soul, may explain the difficulty of the argument.
} 
Renaut, Olivier. «The Analogy Between Vice and Disease from the Republic to the Timaeus ». In Psychology and Ontology in Plato, Luca Pitteloud \& Evan Keeling (eds.), 139:67-83. Cham: Springer International Publishing, 2019. https://doi.org/10.1007/978-3-030-04654-5_6. - pre-proof version.

"Keep in mind, Glaucon, that we don't think that a body is destroyed by the badness of food (i் But if the badness of the food happens to implant in the body an evil proper to a body

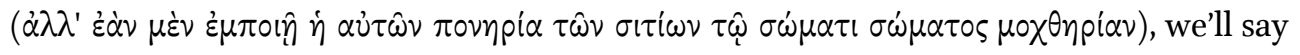
that the body was destroyed by its own evil, namely, disease (i் oüøns). But, since the body is one thing and food another, we'll never judge that the body is destroyed by the badness of food, unless it implants in it the body's own natural

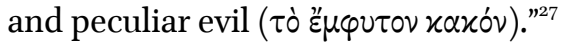

There must be a proper "assimilation" of the body from the badness of food before we can say that the body is diseased. The same argument is then applied to the relation between body and soul.

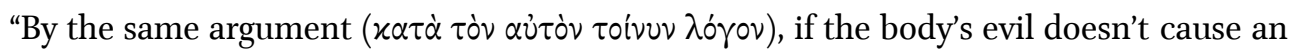
evil in the soul that is proper to the soul, we'll never judge that the soul, in the absence

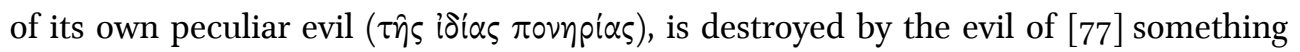
else. We'd never accept that anything is destroyed by an evil proper to something else. ${ }^{28}$

If the body were to be the cause of a psychic vice, it has to bring about first, i.e., to be the occasion for, a proper evil in the soul. The result of this comparison is twofold: to be sure, the body may have some effects on the soul, infecting it with bad "food," so that the soul is being overwhelmed with desires and mortal thoughts; on the other hand, as it is obvious too, the soul cannot be destroyed by fevers, murders, or any other bodily diseases or other accidents: it has to assimilate these bad foods into a proper evil, vice, before being corrupted.

"When something has the evil proper to something else in it, but its own peculiar evil is absent, we won't allow anyone to say that it is destroyed, no matter whether it is a soul or anything else whatever. And you may be sure that no one will ever prove that the souls of the dying are made more unjust by death." ${ }^{29}$

Because we are a composite of body and soul, body and soul remain completely distinct in regard to the causation of their respective corruption. It is of course true that the body is a source for the soul to become vicious, as well as a truism to say that a vicious soul may dispose the body to the "new diseases" that were described from book 3. But the application of the analogy shows, precisely, that it is perfectly possible, from this argument, to have a sick body and a healthy soul ${ }^{30}$ or, reciprocally, to have a vicious soul in a body bursting with vitality, even it is only for a time..$^{3^{1}}$

The argument of book 10 makes clear that the analogy between vice and disease, even if it reveals an isomorphism, should remain asymmetrical. Bodily diseases are powerful images to understand vices; but a disease of the body cannot infect the soul so far as to destroy it; because a soul does not perish even by its proper evil, vice, we must posit, by contrast, that even if a vicious soul does not

\footnotetext{
${ }^{27}$ Rep. 10, 6oge1-610a3.

${ }^{28}$ Rep. 10, 610a5-8.

${ }^{29}$ Rep. 10, 61ob6-c2.

${ }^{30}$ See, for example, Rep. 10, 613a4-7: "Then we must suppose that the same is true of a just person who falls into poverty or disease ( afterwards, for the gods never neglect anyone who eagerly wishes to become just and who makes himself as much like a god as a human can by adopting a virtuous way of life."

${ }^{31}$ Rep. 10, 61od5-e4: "By god, if injustice were actually fatal to those who contracted it, it wouldn't seem so terrible, for it would be an escape from their troubles. But I rather think that it's clearly the opposite, something that kills other people if it can, while, on top of making the unjust themselves lively ( $\mu \dot{\alpha} \lambda \alpha \zeta \omega \tau \omega \dot{\alpha} \nu \tau \alpha \alpha \varepsilon^{\prime} \chi 0 \nu \sigma \alpha \nu$ ), it even brings them out at night. Hence it's very far from being deadly to its possessors."
} 
Renaut, Olivier. «The Analogy Between Vice and Disease from the Republic to the Timaeus ». In Psychology and Ontology in Plato, Luca Pitteloud \& Evan Keeling (eds.), 139:67-83. Cham: Springer International Publishing, 2019. https://doi.org/10.1007/978-3-030-04654-5_6. - pre-proof version.

contaminate the body directly, vice may pave the way to new diseases and bad regimens, as we have seen from book 3 .

\section{From the Republic to the Timaeus}

[78] The Timaeus seems to contradict the conclusions we've reached in the Republic: as it is famously stated in $86 \mathrm{~b} 2$, diseases of the soul, at least some of them, come from bodily states ( $\delta \dot{\alpha} \dot{\alpha}$ $\sigma \omega \dot{\omega} \mu \alpha \tau \varsigma^{\prime} \xi^{\prime \prime}(\nu)$ that have just been described in 81e-86b. However, the conclusions of the Timaeus, as difficult to interpret as they may be, do not contradict the principal claims of the Republic. ${ }^{32}$

First of all, bodily diseases are dysfunctional structures by excess or default. According to the traditional reading of pages 81e-86a of the Timaeus, bodily diseases follow a tripartite division: (1) illnesses coming from an excess or deficiency of one element over the others (air, fire, earth, water), itself implying a disturbance of the qualities (hot, cold, dry and wet, light and heavy) or humors (blood, biles, and phlegms); (2) illnesses coming from secondary constitutions (marrow, bone, flesh, tendons, blood) whose general principle is the inversion of the regeneration process; and (3) illnesses related to humors and wind disorders. ${ }^{33}$ It has been argued, however, rightly in my view, that the first category of diseases is more to be understood as a general principle of the nosology, defining disease as a disorder between elements. ${ }^{34}$ This description is compatible with the structural homology that has been presented in the Republic, where all elementary and composite objects can be called "ill" because of a disruption of their respective natural order and function. Illnesses of the soul too are disruptions of its structure and hierarchical order. ${ }^{35}$ Every disease of the soul coming from madness and ignorance is reducible to a disorganized psychic structure, where reason cannot master pleasures and pains anymore nor emotions such as anger and fear. ${ }^{36}$ Again, a structural homology, relying on the view that both body and soul obey the same general principle of an ordered cosmos, can be inferred from the Timaeus's passage on the bodily and psychic diseases.

Second, the fact that some diseases of the soul emerge ( $\sigma \nu \mu \beta \alpha^{\prime}(v \varepsilon l, 86 \mathrm{~b} 1)$ from a vicious disposition of the body ( $\delta \dot{\alpha} \sigma \dot{\omega} \mu \alpha \tau \sigma \varsigma \varepsilon^{\prime \prime} \xi i \nu, 86 \mathrm{~b} 2$ ) surely does not mean that the cause is exclusively physical. ${ }^{37} \mathrm{It}$ is true that it is an excess of semen in the marrow that causes troubles regarding the acuteness of the feeling of pleasures and pain; it is true too that it is white phlegm, acid phlegm, and bile that disturb the movements [79] of the soul, causing psychic diseases. However, Timaeus not only insists finally on the importance of political institutions and false speeches on the one hand (87a7-b2), and on bad upbringing on the other hand $(87 \mathrm{~b} 2-3)$ regarding the diseases of the soul that depends on ignorance, but he never really claims that the sole cause of these diseases is physical. Admittedly,

\footnotetext{
$3^{2}$ For a useful presentation of the theory of "vice" from the Republic to the Timaeus, see Hackforth (1946) and O'Brien (1967, p. 13).

${ }^{33}$ See Brisson (1994), Cornford (1937), Joubaud (1991), and Taylor (1928).

${ }^{34}$ See Grams (2009) and Prince (2014). Grams presents very precise arguments so as to prove that illnesses in the body follow the same principles that rule the cosmos as a whole: diseases are caused either "by movement into the body, out of the body, or among the elements already present within the body" (162). Prince makes the so-called first "kind" of disease the general principle whose subsequent two kinds are some "subspecies" of the former (915).

${ }^{35}$ Miller (1962) explicitly follow this line of interpretation. See also Lautner (2011).

${ }^{36}$ See Hackforth (1946, p. 119) who notes that the term vóros appears to be the generic term for all these disruptions and not $x \alpha x^{\prime} \alpha$ as in the Sophist.

${ }^{37}$ It is not the place here to recall the very ancient and tight debates on this passage. I rely mostly here on Stalley (1996), Gill (2000), and Steel (2001).
} 
Renaut, Olivier. «The Analogy Between Vice and Disease from the Republic to the Timaeus ». In Psychology and Ontology in Plato, Luca Pitteloud \& Evan Keeling (eds.), 139:67-83. Cham: Springer International Publishing, 2019. https://doi.org/10.1007/978-3-030-04654-5_6. - pre-proof version.

Timaeus refutes a too simple dualism that leads people to blame as voluntary some akratic actions; for if some corrupt condition of the body is clearly responsible, a bad upbringing is alsoinvolved:

"A man becomes evil, rather, as a result of one or another corrupt condition of his body

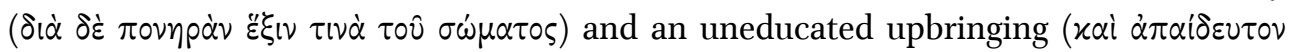

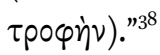

Even if we were to accept that this kind of vice has nothing to do with a perverse bodily condition, we would be wrong to blame it, according to Timaeus, for the upbringing is within the remit of the lawgivers, parents, and educators. In other words, diseases of the soul are more probably a conjunction of two causes, a physical one that gives the occasion for a vice to appear and a psychic one that makes the agent unwilling to control his appetites, pleasures, and pains. The conclusions of book 10 of the Republic may be insightful here: just as it was necessary in the Republic for a soul to assimilate the bad condition of a body (disease) in developing its own and proper evil (vice), without conflating each of these bad conditions, in the Timaeus, the soul is challenged with diseases to master these disturbances $(\pi \alpha \theta \eta \dot{\eta} \mu \tau \alpha)$, allowing them to influence its own movements or not. ${ }^{39}$

As a matter of fact, Timaeus precisely does not conflate physical and psychic conditions, as the example of the "sacred disease" shows. At $85 \mathrm{a} 5-\mathrm{b} 2$, in the context of the bodily diseases, Timaeus describes the cause of the so-called sacred disease (probably epilepsy), saying that it comes from white phlegm mixed with black bile, whose diffusion stands in the circuits of the head.

"If it is mixed with black bile and the mixture is sprayed against the divine circuits in the head, thereby throwing them into confusion, the effect is fairly mild if it comes during sleep, but should it come upon someone while awake, it is much harder to shake off. Seeing that it is a disease of the sacred part of our constitution, it is entirely just that

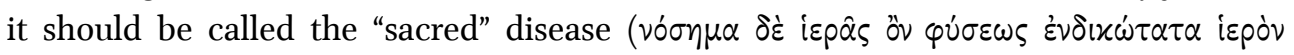
$\lambda \varepsilon \dot{\gamma} \gamma \tau \alpha \mathrm{ll}) .{ }^{40}$

The "sacred disease" is for Timaeus nothing "sacred" in the sense that the disease would come from the action of a god-on this point the physician agrees with the author of the Hippocratic treatise Sacred disease ${ }^{41}$; but Timaeus invokes another [80] meaning of the expression, saying that it is "sacred" for it obscures intellect, which is admittedly the most precious part of our own soul. Later in $87 \mathrm{a}$, dealing with the diseases of the soul, the very same causes (phlegm and bile combined) are said to provoke oblivion or forgetfulness and dullness when they reach the highest part of the soul:

"When any of a man's acid and briny phlegms or any bitter and bilious humors wander up and down his body without finding a vent to the outside and remain pent up inside, they mix the vapor that they give off with the motion of the soul and so are confounded with it. So they produce all sorts of diseases of the soul, some more intense and some more frequent than others. And as they move to the three regions of the soul, each of them produces a multitude of varieties of bad temper and melancholy in the region it

\footnotetext{
${ }^{38}$ Tim. $86 \mathrm{~d} 7$-e2.

${ }^{39}$ Tim. 42a3-b2.

${ }^{40}$ Tim. 85a5-b2.

${ }^{41}$ See Sacred Disease, sec. V (=2 Littré): "But this disease is in my opinion no more divine than any other; it has the same nature as other diseases, and the cause that gives rise to individual diseases. (...) Another strong proof that this disease is no more divine than any other is that it affects the naturally phlegmatic, but does not attack the bilious. Yet, if it were more divine than others, this disease ought to have attacked all equally, without making any difference between bilious and phlegmatic" (trans. W.H.S. Jones in Hippocrates (1923)).
} 
Renaut, Olivier. «The Analogy Between Vice and Disease from the Republic to the Timaeus ». In Psychology and Ontology in Plato, Luca Pitteloud \& Evan Keeling (eds.), 139:67-83. Cham: Springer International Publishing, 2019. https://doi.org/10.1007/978-3-030-04654-5_6. - pre-proof version.

attacks, as well as of recklessness and cowardice, not to mention forgetfulness and stupidity." ${ }^{42}$

Timaeus gives us then two outcomes of the same causes that are not similar-a mere physical one in the former passage (a seizure) and some intellectual defects in the latter. One might say that the same causes may not have the same effects, but it would be better to say that in the former case, one may have a bodily disease that affects his intellect temporarily, whereas in the latter case, the vices that are mentioned are avoidable in training the soul so as to resist some overcoming vapors. There is, indeed, a difference between a seizure and a permanent disposition that comes, maybe from a bodily condition but surely from a bad upbringing.

Third, one may even go further in the Timaeus, saying that a good regime, led by a virtuous soul, may stand for a good criterion to diagnose what kind of cause is involved in a bodily disease. In the passage devoted to the bodily diseases, Timaeus makes a continuous use of political metaphor to describe them. ${ }^{43}$ We can interpret these metaphors in the line of the Republic: (a) there is an isomorphism between the city and the soul, and just as the body is sick because of its elements, the city is disorganized because of the stasis between its unequal components, and (b) the comparison has a common reference to a general cosmic order, to borrow G. Lloyd's word, that "span [s] the fields of politics, morality, 'physics' (the nature of things) and the body in particular" ${ }^{44}$. We can note, however, that in the Timaeus, the political metaphor informs the way we see the body, and not the other way round, so that it would be more correct to say that just as the city is disorganized because of the stasis between its unequal components, so the body is sick because of the battle between its elements. In other words, we find, even in the Timaeus, an asymmetrical position of the analogy between soul (and or city) and body, for it is always [81] ultimately to an ethical and political end that a right description of what depends on it (health and physical upbringing) is answerable ${ }^{45}$. Bodily diseases can of course be natural; but their cure is overdetermined by an ethical and political end that prescribes the correct regimen. The apparent symmetry that we find in the Timaeus between body and soul ( $88 \mathrm{~b} \mathrm{ff}$.) should not obliterate the main responsibility of the soul in governing its parts and the bodily parts that depend on it.

\section{Conclusion: Norms of Disease}

Plato is no doctor. But as a philosopher, he does not hesitate to give his own interpretation of what medicine is and of what its history should be. Plato is not G. Canguilhem either ${ }^{46}$, but a functionalist paradigm that applies to psychic, physical, and psychosomatic structures leads to an axiological overdetermination of diseases and their typologies. In using the analogy between disease and vice, Plato does not align psychic illness with physical necessity; on the contrary, physical necessity is informed and better mastered by the intellect's rule.

\footnotetext{
${ }^{42}$ Tim. 86e3-87a7.

${ }^{43}$ Tim. 82a2-4, "unnatural pleonexia" ( $\dot{\eta} \pi \alpha \rho \dot{\alpha} \varphi v ́ \sigma \iota \nu \pi \lambda \varepsilon \circ \nu \varepsilon \xi \dot{\xi} \alpha$ ) prevails among the elements; 83a3-5, tissues and byproducts of blood are feuding among themselves and make war against whatever stays at its post $(\dot{\varepsilon} \chi \theta p \dot{\alpha} \mu \dot{\varepsilon} \nu \alpha \dot{\tau} \tau \dot{\alpha}$

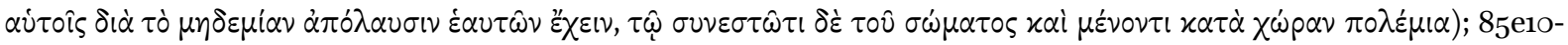
a1, the body is said to master $(\varkappa \rho \alpha \tau \eta \varepsilon \hat{\imath} \sigma \alpha)$ the dissolution of the bile, and then by-products are expelled just like they

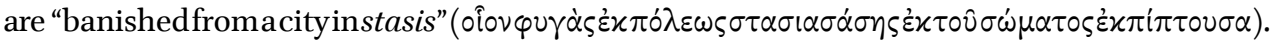

${ }^{44}$ Lloyd (2003, p. 156).

${ }^{45}$ I agree with the claim that medicine offers us a normative account of diseases, as Jorgenson (2018, p. 113) shows.

${ }^{46}$ Canguilhem (1966/2009).
} 
Renaut, Olivier. «The Analogy Between Vice and Disease from the Republic to the Timaeus ». In Psychology and Ontology in Plato, Luca Pitteloud \& Evan Keeling (eds.), 139:67-83. Cham: Springer International Publishing, 2019. https://doi.org/10.1007/978-3-030-04654-5_6. - pre-proof version.

I would like finally to comment on an intriguing passage from the Republic that reveals both the fecundity and the limits of the vice-disease analogy or shows, what amounts to the same claim, how Plato considers the place of the doctor in the city of the Republic.

"The cleverest doctors are those who, in addition to learning their craft, have had contact

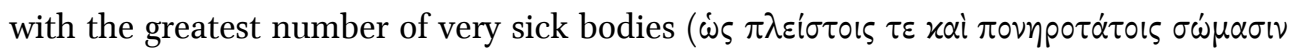

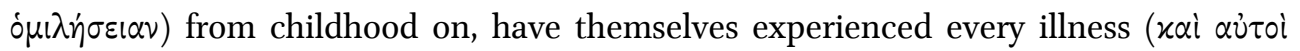

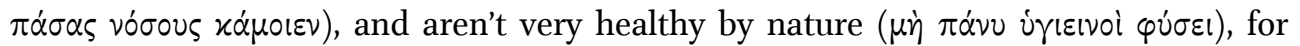
they don't treat bodies with their bodies, Isuppose-if they did, we wouldn't allow their bodies to be or become bad. Rather, they treat the body with their souls $(\dot{\alpha} \lambda \lambda \dot{\alpha} \psi v \times \hat{n}$ $\sigma \hat{\omega} \mu \alpha)$, and it isn't possible for the soul to treat anything well, if it is or has been bad itself. — That's right. - As for the judge, he does rule other souls with his own soul

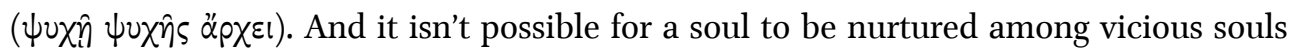

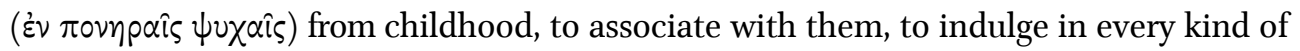
injustice, and come through it able to judge other people's injustices from its own case, as

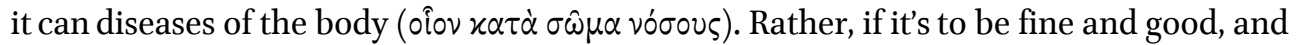
a sound judge of just things, it must itself remain pure and have no experience of bad character while it's young. That's the reason, indeed, that decent people appear simple and easily deceived by unjust ones when they are young. It's because they have no models in themselves of the evil experiences of the vicious to guide their judgments." ${ }^{47}$

[82] Doctors learn by experience, and they should themselves experience (at least as in a vaccine trial) bodily diseases in order to treat them well. Because the doctors treat bodies with their soul (diagnosis, prescription of a regimen), they do not need to be healthy. Doctors should have theoretical knowledge of diseases from these experiences, through a kind of inductive process, but the experience of diseases enables them to be more attentive to the specificities of the body ${ }^{48}$. The diseases of the body can be, so it is supposed, at least neutralized as such, without influencing the soul itself. By contrast, the judge should never experience vice so as to know them: there is no form of vice, and the only criterion of judgment is virtue itself. The knowledge of human nature does not rest on the experience of vicious actions and characters but on knowledge proper, so as to define for each natural being its proper good. The asymmetrical position of the doctor and the judge regarding the good gives an account of why health is no more than a secondary good, depending on the good of the soul, which is virtue. The analogy between vice and disease in the Republic, and further in the Timaeus, may work so as to understand vice through bodily disease, but virtue and knowledge is the ultimate criterion to grasp the norms that are involved in our diagnosis of disease. $^{49}$

\footnotetext{
${ }^{47}$ Rep. 3, 408dio-4ogbi.

${ }^{48}$ Strong arguments are given by Betegh (forthcoming) to account for a relative autonomy of the body in the late dialogues.

${ }^{49}$ See Tim. 88a3-7 for an example of a bad diagnosis because of the inability of the doctor to recognize the right cause of the disease: “(...) in teaching and controversy, public or private, she inflames and racks its fabric through the rivalries and contentions that arise, and bringing on rheums deludes most so-called physicians making misguided

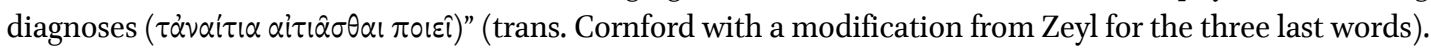


Renaut, Olivier. «The Analogy Between Vice and Disease from the Republic to the Timaeus ». In Psychology and Ontology in Plato, Luca Pitteloud \& Evan Keeling (eds.), 139:67-83. Cham: Springer International Publishing, 2019. https://doi.org/10.1007/978-3-030-04654-5_6. - pre-proof version.

\section{References}

Adam, J. N. (1969). The Republic of Plato (Vol. II). Cambridge, UK: Cambridge University Press. Blössner, N. (2007). The city-soul analogy. In G. R. F. Ferrari (Ed.), The Cambridge Companion to

Plato's Republic (pp. 345-385). Cambridge, UK: Cambridge University Press.

Brisson, L. (1994). Le Même et l'autre dans la structure ontologique du Timée de Platon: un commentaire systématique du Timée de Platon. Sankt Augustin, Germany: Academia Verlag.

Brock, R. (200o). Sickness in the body politic: Medical imagery in the Greek polis. In V. Hope \&

E. Marshall (Eds.), Death and disease in the ancient city (pp. 24-34). London, UK: Routledge. Brown, E. A. (2011). A defense of Plato's argument for the immortality of the soul at Republic X

6o8c-611a. Apeiron, 30(3), 211-238. https://doi.org/10.1515/APEIRON.1997·30.3.211

Canguilhem, G. (2009). Le normal et le pathologique. Paris: Presses universitaires de France (Original work published 1966).

Cooper, J. M., \& Hutchinson, D. S. (1997). In Plato (Ed.), Complete works. Indianapolis, IN: Hackett.

Cornford, F. M. (1937). Plato's cosmology: The Timaeus of Plato. London, UK: Routledge \& Kegan Paul.

Demont, P. (2013). Progrès ou décadence de la technè médicale selon [Hippocrate], Ancienne Médecine et Platon, République. Études platoniciennes, (10). https://doi.org/10.400o/etudes platoniciennes. 365

Gill, C. (2000). The body's fault? Plato's timaeus on psychic illness'. In M. R. Wright (Ed.), Reason and Necessity in Plato's Timaeus (pp. 59-84). London, UK: Classical Press of Wales, Duckworth.

Grams, L. (2009). Medical theory in Plato's “Timaeus”. Rhizai: A Journal for Ancient Philosophy and Science, 6(2), 161-192.

Hackforth, R. (1946). Moral evil and ignorance in Plato's ethics. The Classical Quarterly, 40(3/4), 118120.

Hippocrates. (1923). Hippocrates (Vol. II) (W. H. S. Jones, Trans.). London, UK: W. Heinemann. Jorgenson, C. (2018). The embodied soul in Plato's later thought. Cambridge, UK: Cambridge University Press.

Joubaud, C. (1991). Le corps humain dans la philosophie platonicienne : étude à partir du "Timée". Paris, France: J. Vrin.

Kosak, J. C. (2000). Polis nosousa. Greek ideas about the city and disease in the fifth century BC. In V. Hope \& E. Marshall (Eds.), Death and disease in the ancient city (pp. 35-54). London, UK: Routledge.

Lautner, P. (2011). Plato's account of the diseases of the soul in Timaeus 86B1-87B9. Apeiron, 44(1), 22-39. https://doi.org/10.1515/apeiron.2011.004

Lloyd, G. E. R. (2003). In the grip of disease: studies in the Greek imagination. Oxford, UK: Oxford University Press.

Macé, A. (2006). Platon, philosophie de l'agir et du pâtir. Sankt Augustin, Germany: Academia Verlag.

Macé, A. (2010). Santé des corps, des esprits, des cités : un modèle antique de liaison entre pathologie sociale et pathologie psychique. In S. Haber (Ed.), Des Pathologies sociales aux pathologies mentales (pp. 31-54). Besançon, France: Annales Littéraires de Franche-Comté.

Mansfeld, J. (1980). Plato and the method of Hippocrates. Greek, Roman, and Byzantine Studies, $21(4), 341-362$. 
Renaut, Olivier. «The Analogy Between Vice and Disease from the Republic to the Timaeus ». In Psychology and Ontology in Plato, Luca Pitteloud \& Evan Keeling (eds.), 139:67-83. Cham: Springer International Publishing, 2019. https://doi.org/10.1007/978-3-030-04654-5_6. - pre-proof version.

Miller, H. W. (1962). The aetiology of disease in Plato's Timaeus. Transactions and Proceedings of the American Philological Association, 93, 175-187. https://doi.org/10.2307/28376o

O'Brien, M. J. (1967). The Socratic paradoxes and the Greek mind. Chapel Hill, NC: University of North Carolina Press.

Prince, B. D. (2014). The metaphysics of bodily health and disease in Plato's Timaeus. British Journal for the History of Philosophy, 22(5), 908-928. https://doi.org/10.1080/o9608788.20 14.988599

Renaut, O. (2017). Political images of the soul. In R. Edmonds III \& P. Destrée (Eds.), Plato and the power of images (pp. 138-157). Leiden, Netherlands: Brill. https://doi.org/10.1163/ 9789004345010_010

Stalley, R. F. (1981). Mental health and individual responsibility in Plato's Republic. The Journal of Value Inquiry, 15(2), 109-124.

Stalley, R. F. (1995a). Punishment in Plato's Laws. History of Political Thought, 16(4), 469-487. Stalley, R. F. (1995b). Punishment in Plato's Protagoras. Phronesis, 4o(1), 1-19.

Stalley, R. F. (1996). Punishment and the physiology of the Timaeus. The Classical Quarterly, 46(2), 357-370.

Steel, C. (2001). The moral purpose of the human body. A reading of Timaeus 69-72. Phronesis, 46(2), $105^{-128 .}$

Taylor, A. E. (1928). A Commentary of Plato's Timaeus. Oxford, UK: Clarendon Press. 